\title{
Evaluation of new laser spectrometer techniques for in-situ carbon monoxide measurements
}

\author{
C. Zellweger, M. Steinbacher, and B. Buchmann \\ Empa, Swiss Federal Laboratories for Materials Testing and Research, Laboratory for Air Pollution/Environmental \\ Technology, 8600 Dübendorf, Switzerland
}

Correspondence to: C. Zellweger (christoph.zellweger@empa.ch)

Received: 8 June 2012 - Published in Atmos. Meas. Tech. Discuss.: 12 July 2012

Revised: 1 October 2012 - Accepted: 2 October 2012 - Published: 30 October 2012

\begin{abstract}
Long-term time series of the atmospheric composition are essential for environmental research and thus require compatible, multi-decadal monitoring activities. The current data quality objectives of the World Meteorological Organization (WMO) for carbon monoxide (CO) in the atmosphere are very challenging to meet with the measurement techniques that have been used until recently. During the past few years, new spectroscopic techniques came to market with promising properties for trace gas analytics. The current study compares three instruments that have recently become commercially available (since 2011) with the best currently available technique (Vacuum UV Fluorescence) and provides a link to previous comparison studies. The instruments were investigated for their performance regarding repeatability, reproducibility, drift, temperature dependence, water vapour interference and linearity. Finally, all instruments were examined during a short measurement campaign to assess their applicability for long-term field measurements. It could be shown that the new techniques perform considerably better compared to previous techniques, although some issues, such as temperature influence and cross sensitivities, need further attention.
\end{abstract}

\section{Introduction}

Measurements of carbon monoxide (CO) have been taken using a large number of different measurement techniques. The most commonly applied analytical methods are gas chromatographic techniques combined with either mercuric oxide $(\mathrm{HgO})$ reduction detection (Gros et al., 1999; Novelli, 1999) or a flame ionization detector (FID) (van der Laan et al., 2009), and photometric methods, such as non-dispersive infrared absorption (NDIR) (Nedelec et al., 2003; Parrish et al., 1994), vacuum ultra-violet resonance fluorescence (VURF) (Gerbig et al., 1999) and tuneable diode laser spectroscopy (TDLS) (Fried et al., 1991). Despite the importance of $\mathrm{CO}$ in the troposphere as the dominant sink for the hydroxyl radical (Logan et al., 1981) and the reasonably large numbers of different analytical techniques, there is still a considerable remaining uncertainty in the determination of the atmospheric mixing ratio of $\mathrm{CO}$. To address this issue, a number of comparison studies have been performed $(\mathrm{Ou}$ Yang et al., 2009; Zellweger et al., 2009).

More recently, new analytical techniques became commercially available for the measurement of $\mathrm{CO}$. These techniques include closed-path Fourier Transform Infrared (FTIR) absorption, cavity-enhanced off-axis Integrated Cavity Output Spectroscopy (ICOS), multi-path Quantum Cascade Laser (QCL) absorption in the mid-infrared range, and Cavity Ring-Down Spectroscopy (CRDS) in the near-infrared range.

To date, no comparison studies including the above techniques have been published. This work presents the first evaluation of the performance of three new and commercially available CO analysers (Picarro G2401, Aerodyne Mini-QCL and Los Gatos LGR-23d) in comparison with the VURF technique and complements a previous publication that reported a comparison of $\mathrm{HgO}$, FID, NDIR and VURF techniques (Zellweger et al., 2009). In addition to a four day comparison of ambient air measurements, the instruments have been characterised for precision, drift, linearity, temperature dependence and the influence of water vapour on corresponding mole fractions of carbon monoxide. 


\section{Instruments and methods}

The following analytical techniques were used for this comparison study:

- VURF: Vacuum UV resonance fluorescence measurements were taken with an Aerolaser AL5001 analyser (Aerolaser $\mathrm{GmbH}$, Germany). The instrument was calibrated every $3 \mathrm{~h}$ using a natural-air working standard. The operating gases were $\mathrm{CO}_{2}(99.995 \%)$ in $\operatorname{Ar}(99.9999 \%)$ and $\mathrm{N}_{2}(99.9999 \%)$ with a purifier (Aeronex Gate Keeper SS-400KGC-I-4S). The instrument sensitivity was between 47.7-49.4 counts per second (cps) per ppb. The VURF technique is based on the fluorescence of CO at $150 \mathrm{~nm}$ (Gerbig et al., 1999). The discharge of a CO resonance lamp, excited by a radio frequency discharge, is filtered and directed by three $\mathrm{CaF}_{2}$ lenses into the fluorescence chamber with a photomultiplier tube.

- CRDS: For the Cavity Ring-Down Spectroscopy, a Picarro $\mathrm{G} 2401 \mathrm{CO} / \mathrm{CH}_{4} / \mathrm{CO}_{2} / \mathrm{H}_{2} \mathrm{O}$ analyser (Picarro Inc., CA, USA) was used. The instrument was calibrated every $12 \mathrm{~h}$ using a natural-air working standard during ambient air measurements. The sample air was not dried, and no further correction was applied to the $\mathrm{CO}$ mole fraction reported by the instrument since the analyser applies an internal correction (for interferences of $\mathrm{H}_{2} \mathrm{O}$, $\mathrm{CO}_{2}$, etc.). The CRDS technique deploys an optical cavity with highly reflective mirrors where the optical absorbance of the $\mathrm{CO}$ is determined by the light dissipation rate in the optical cavity. Light at a specific wavelength from a near-infrared laser source is injected into the optical cavity through a partially reflecting mirror. The light intensity inside the cavity increases over time, which is monitored through a second partially reflecting mirror using a photo detector located outside the cavity. The ring-down measurement is then taken by switching off the laser and measuring the time constant of the exponential decay of the light intensity. This technique has been successfully implemented in greenhouse gas analysers (Crosson, 2008).

- ICOS-QCL: A cavity-enhanced off-axis Integrated Cavity Output Spectroscopy (ICOS) (Baer et al., 2002) Quantum Cascade Laser (QCL) instrument (Los Gatos Research Inc. (LGR), CA, USA, model LGR-23d) $\mathrm{CO} / \mathrm{N}_{2} \mathrm{O} / \mathrm{H}_{2} \mathrm{O}$ analyser was used for the instrument tests and comparison. Instruments based on off-axis ICOS employ a tuneable laser and an optical cavity as the measurement cell, like all the cavity-enhanced absorption spectroscopy methods. As a result, the effective optical path length is determined by the reflectivity of the cavity mirrors and can be thousands of metres. However, unlike other cavity-enhanced methods, the beam trajectory through the cavity is not unique, dedicated optical isolation from the cavity is not required, and there are no constraints on the laser beam shape. Measurements of gas mole fractions are based on fully resolved absorption spectra obtained by continuously and repetitively tuning the laser wavelength over a spectral region that includes absorption features of the target gas(es). The mole fraction of the target gas is determined from the area under the measured line shape, gas temperature, gas pressure and optical path length using Beer's Law. The instrument used for our study was not featuring the enhanced performance package with improved thermal control of the cavity. The same calibration scheme as for the CRDS instrument was applied during ambient air measurements. The water vapour interference was corrected with an experimentally determined correction function (see following section).

- Mini-QCL: An Aerodyne Quantum Cascade Laser Mini Monitor (Aerodyne Research Inc., MA, USA) with an astigmatic multiple-pass absorption cell was used (McManus et al., 2010, 2011). In contrast to the other instruments, no active pressure control of the measurement cell has been implemented in this analyser. A water vapour correction and calibration analogous to that of the ICOS-QCL instrument was done. The detection method for the Aerodyne Research instrument uses rapid-sweep, $3 \mathrm{kHz}$, direct absorption spectroscopy using a continuous-wave quantum cascade laser implemented with the data collection and analysis programme TDLWINTEL. The laser current is set below the threshold at the end of each sweep to determine the zero light level for the absorption measurement, which allows absolute trace gas mole fractions to be calculated from spectroscopic parameters in the HITRAN database using the measured pressure and temperature within the absorption cell. The addition of a germanium etalon determines the laser tuning rate. With a fixed path length of $76 \mathrm{~m}$, an astigmatic Herriott cell provides long absorption path lengths (Nelson et al., 2006).

All experiments were carried out in an air-conditioned laboratory $\left(23.5 \pm 1.0^{\circ} \mathrm{C}\right)$ except for the temperature gradient experiments, where the laboratory was actively cooled and heated.

Ambient air measurements were carried out using an air inlet with a common glass manifold, which was flushed at a high flow rate in order to shorten the residence time of the air in the inlet system. Each instrument was connected to the manifold with 1/4-inch Synflex-1300 tubing, and these lines were additionally flushed by external pumps to minimise potential time lags. The ambient air comparison was performed at the Empa campus in Dübendorf, a suburban area of Zürich, Switzerland.

- Calibration: All instruments were calibrated using working standards containing $\mathrm{CO}$ in natural air. The 


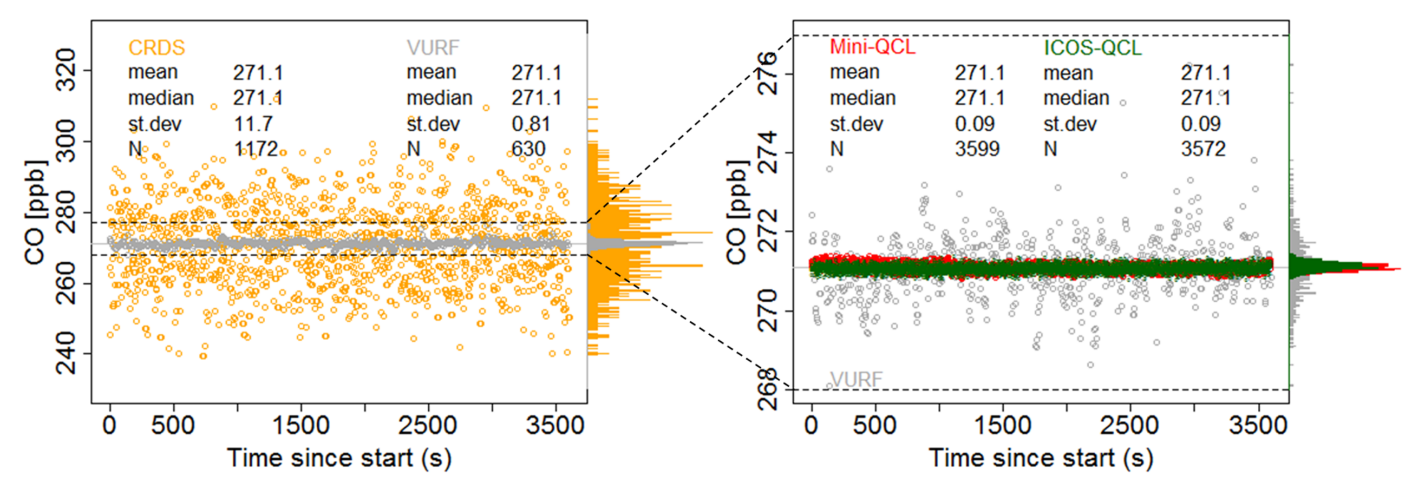

Fig. 1. Instrumental precision (noise) over a 1-h period for the highest possible time resolution (CRDS and VURF, $3.1 \mathrm{~s}$ and $5.7 \mathrm{~s}$, left panel) and 1-s data (Mini-QCL and ICOS-QCL, right panel). The frequency distribution of individual measurement values is shown as a histogram on the right of each plot. The black dashed lines illustrate the different y-axis scales, and the VURF data (grey) are also shown in the right panel.

working standards were calibrated against certified NOAA/ESRL (National Oceanic and Atmospheric Administration/Earth System Research Laboratory) standards, WMO-2004 CO calibration scale.

A definition of the terminology used in this document can be found in the WMO/GAW (World Meteorological Organization/Global Atmosphere Watch Glossary of QA/QC-Related Terminology (2010).

\section{Results}

To investigate the performance of the different instruments, several tests (instrument noise and drift, temperature dependence, linearity, water vapour correction) were carried out; the results of these experiments are summarised in the following sections. To complete the comparison, parallel measurements of ambient air were taken with all four instruments to assess the compatibility of the different analytical techniques in the field. Finally, a summary highlighting pros and cons of the different techniques with respect to long-term field applications is presented.

\subsection{Instrument tests}

\subsubsection{Noise and drift}

To determine the short-term analytical noise of the instruments, a working standard containing natural air was measured simultaneously with all four instruments over a period of one hour. During this time, no calibrations were applied to the analysers; however, all data were normalised to the same $\mathrm{CO}$ mole fraction. Figure 1 shows the instrumental noise over a 1-h period for all instruments at a $1-\mathrm{Hz}$ time resolution (Mini-QCL and ICOS-QCL) and at the highest possible time resolution (CRDS, $0.33 \mathrm{~Hz}$; VURF, $0.18 \mathrm{~Hz}$ ). It can be seen that the precision of the VURF technique is approximately one order of magnitude higher compared to CRDS, and the
QCL instruments are one order of magnitude more precise compared to VURF. However, for long-term monitoring programmes, such high temporal resolution is not required, and appropriate averaging intervals will lead to compatible data with all techniques. The precision of the tested ICOS-QCL analyser was slightly better (standard deviation of $0.09 \mathrm{ppb}$ over one hour at $271.1 \mathrm{ppb} \mathrm{CO}$ ) compared to data acquired with a prototype instrument ( $0.2 \mathrm{ppb}$ over $10 \mathrm{~min}$ at $32.7 \mathrm{ppb})$ (Provencal et al., 2005).

A further aspect that potentially compromises the instrument performance is instrument drift, i.e. changing sensitivity of instrument response with time. To assess the drift of the instruments in environmentally well-controlled conditions, the same working standard as above was measured simultaneously with all instruments over a 10 -h period. The results are presented in Fig. 2 based on 1-min averages for all analysers. It can be seen that all instruments show a significant drift within this 10-h period except for the CRDS technique; however, the much larger instrument noise makes it more difficult to detect small drifts in the sub-ppb range with this technique. In contrast, due to the very high precision, even a small drift of less than $0.1 \mathrm{ppb} \mathrm{CO}$ over a period of minutes to hours can be detected with the QCL instruments. It should be noted that all individual 1-min values were within $\pm 0.5 \mathrm{ppb}$ (Mini-QCL) and $\pm 0.1 \mathrm{ppb}$ (ICOS-QCL) over the 10-h period. This is well within the Data Quality Objectives (DQOs) of the Global Atmosphere Watch (GAW) programme of the World Meteorological Organization (WMO) of $\pm 2 \mathrm{ppb}$ (WMO, 2010).

The optimal averaging times as well as the optimal frequency of calibrations can be estimated using Allan standard deviation plots (Werle et al., 1993). Figure 3 shows Allan plots using the above data (highest possible time resolution) for all instruments. As indicated by the drift plots, longer integration times lead to better results for the CRDS instrument. No obvious drift was observed within a 1-h period; however, the standard Allan deviations do not become 

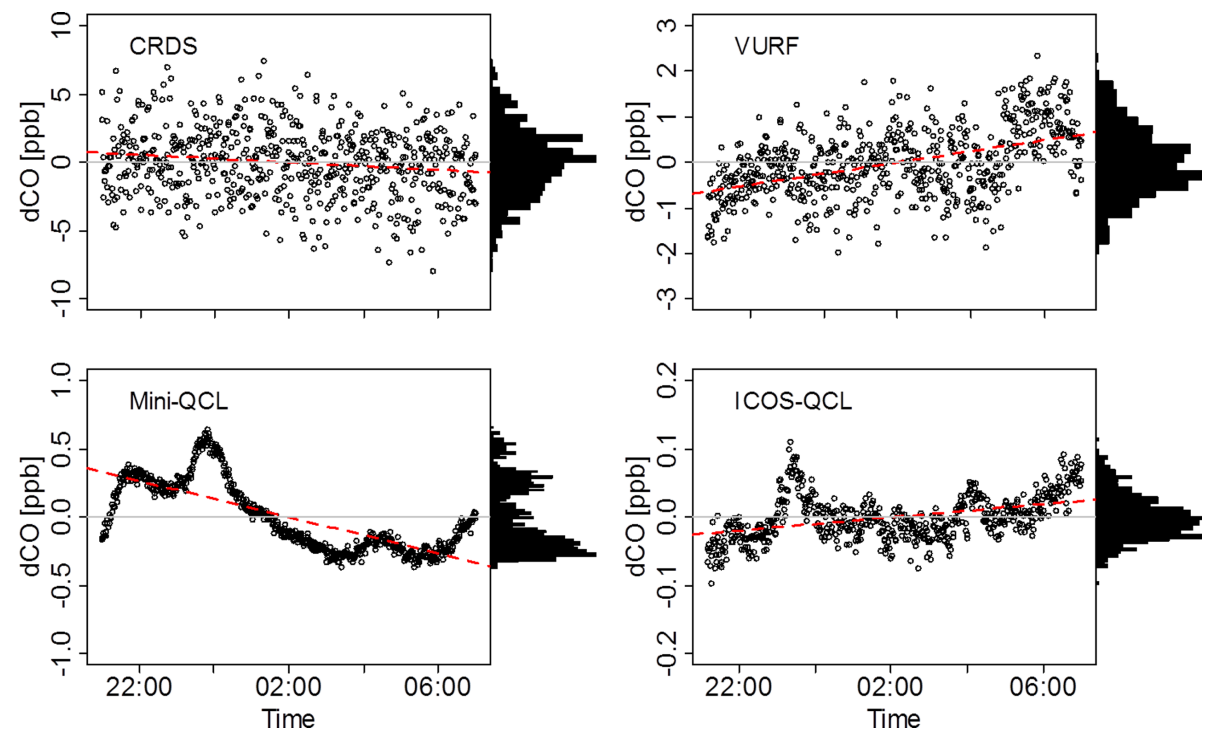

Fig. 2. Instrument drift over a 10-h period for 1-min data. The deviation from the mean value is shown for each data point. The red line depicts the linear regression line. The frequency distribution of individual measurement values is shown as a histogram on the right of each plot. Please take note of the different y-axis scales of the different panels.
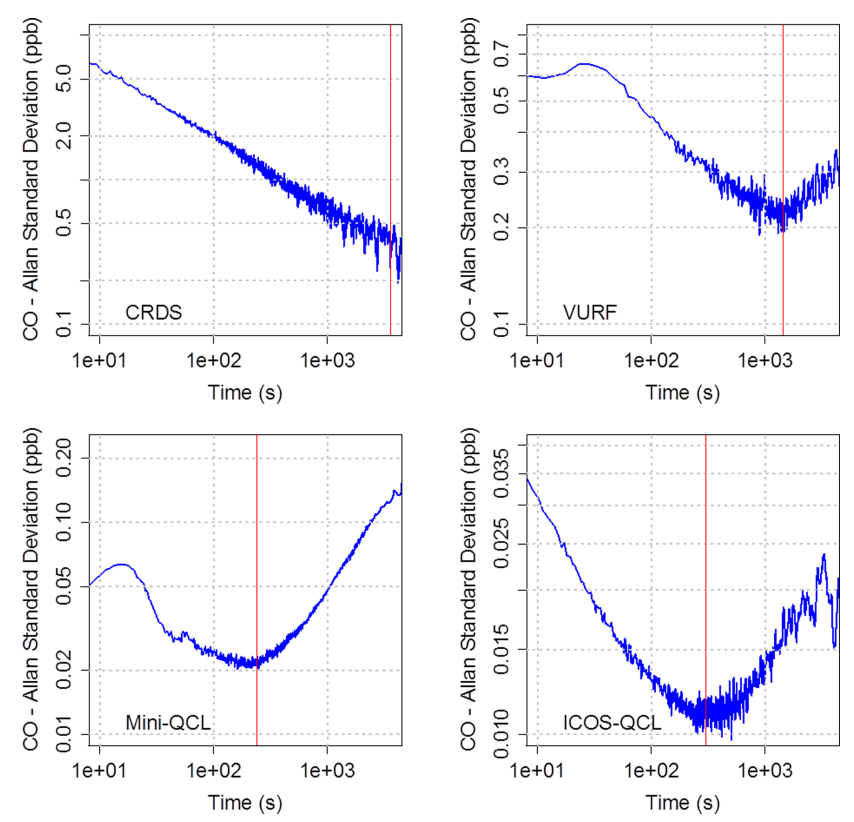

Fig. 3. Allan standard deviation plots for all tested instruments. The lowest Allan standard deviation indicates the optimum averaging time (red vertical lines; CRDS 1 h, VURF 24 min, Mini-QCL 4 min, ICOS-QCL $5 \mathrm{~min}$ ). Please take note of the different y-axis scales of the different panels. The $\mathrm{x}$-axis (in logarithmic scale) spans $60 \mathrm{~min}$.

significantly smaller if longer time aggregates are calculated. Therefore, the optimal averaging time for the CRDS instrument is considered to be one hour. This makes the instrument suitable for long-term monitoring programmes where no higher temporal time resolution than one hour is required.

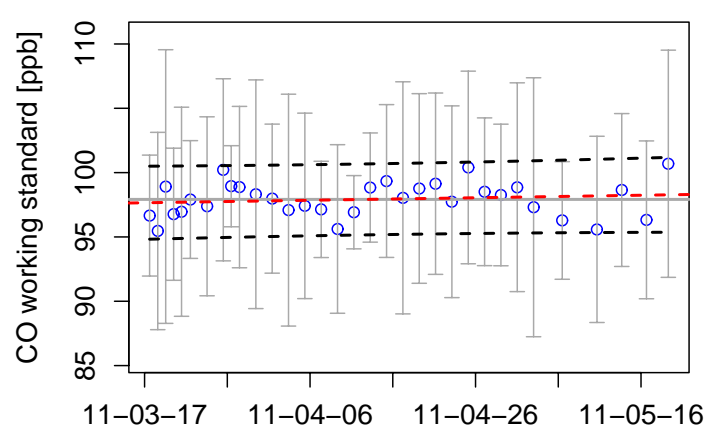

Fig. 4. Reproducibility of a 97.9-ppb working standard measured with a CRDS instrument over the period of 2 months. Each measurement (open blue circles) denotes the average of ten 1-min values. The individual error bars indicate the uncertainty of these measurements $(k=2)$; the red dotted line is the linear regression over time, and the black dotted lines are the $95 \%$ confidence bands of the linear regression.

Figure 4 shows the reproducibility of a working standard with $97.9 \mathrm{ppb}$ of $\mathrm{CO}$ measured in intervals of one to three days over a two-month period with the CRDS analyser. The working standard was measured over a period of $15 \mathrm{~min}$, and the last ten 1-min data were used for the calculation of the average and the standard deviation. Over this period, no significant drift was observed, although the uncertainties of individual measurements of the working standard are relatively high due to short-term instrument noise. Consequently, standard measurements should be pooled for post-analysis data processing to avoid a bias due to short-term noise. The same issue has already been described for the NDIR technique, which also has been shown to produce accurate $\mathrm{CO}$ data if 

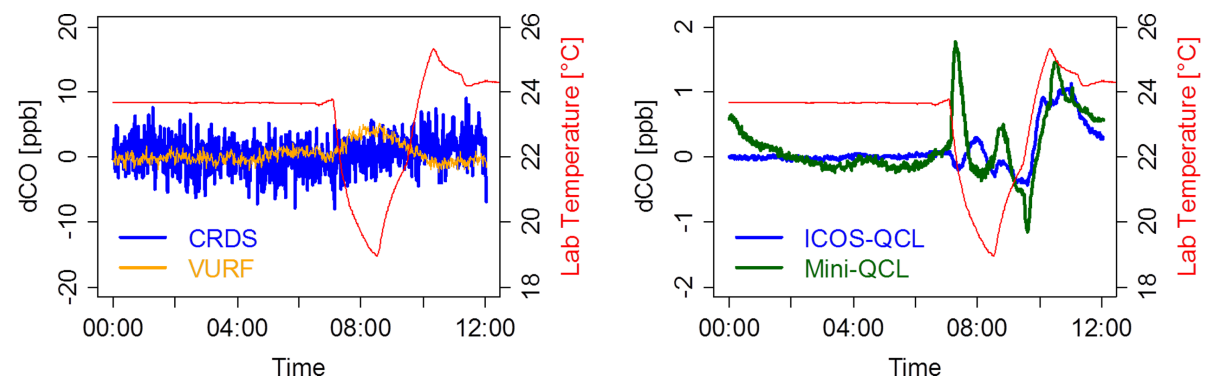

Fig. 5. Influence of the temperature on CO measurements. Left panel: VURF and CRDS, right panel: Mini-QCL and ICOS-QCL, all 1-min data. The deviation of $\mathrm{CO}(\mathrm{dCO})$ to the mean value during the period with constant temperature (00:00-07:00 LT) is shown on the left axis, and the laboratory temperature (red) is shown on the right axis.

appropriate zero and span calibrations are applied (Zellweger et al., 2009).

The VURF technique showed an optimal averaging time of approx. $20 \mathrm{~min}$; afterwards, drift lead to increased uncertainties. However, calibration intervals of $3 \mathrm{~h}$ are usually sufficient for meeting the WMO GAW DQOs. In contrast to the CRDS technique, VURF requires regular calibration due to degradation of the sensitivity over time. This is mainly caused by staining of the optics due to decomposition of e.g. organic compounds in UV $(150-160 \mathrm{~nm})$ light, which also makes the technique maintenance-intensive. Usually, cleaning of the optics is required once per year under normal operating conditions.

For the QCL instruments, the optimal integration time was approximately 2 to $5 \mathrm{~min}$, but drift was only a significantly contributing factor for the Mini-QCL analyser. The ICOSQCL proved to be stable within $\pm 0.1 \mathrm{ppb}$ CO over a 10 -h period. This indicates that the QCL-based techniques do not only have a large potential for long-term monitoring, but are also suitable for highly temporally-resolved data as well as for flux measurements when appropriate measurement cell flushing times are provided.

\subsubsection{Temperature dependence}

The above experiments were carried out under environmentally well-controlled conditions with temperature variations of less than $\pm 0.5^{\circ} \mathrm{C}$, but not all measurement sites provide these conditions. Temperature changes potentially influence the measurements e.g. through line broadening, changes in laser intensities and detector sensitivities. Therefore, the influence of temperature variations was tested by measuring a working standard simultaneously with all four instruments over a 12 -h period. For the first seven hours, the air temperature was kept constant at $23.7 \pm 0.2{ }^{\circ} \mathrm{C}$; afterwards, the laboratory was cooled to $19.0^{\circ} \mathrm{C}$ within $84 \mathrm{~min}$, and then heated to $25.3^{\circ} \mathrm{C}$ within additional $110 \mathrm{~min}$. Figure 5 shows the change in $\mathrm{CO}$ mole fraction (1-min data) as a function of temperature and time. Such temperature changes correspond to worst-case scenarios as they may happen in poorly airconditioned environments. It can be seen that all instruments respond to temperature changes except for the CRDS instrument. However, small changes in the mole fractions are more difficult to detect with this instrument due to the relatively large analytical noise. Nevertheless, the temperature of the cavity of the CRDS analyser is thermally very stable, and the temperature change also showed no significant influence on the $\mathrm{CH}_{4}$ and $\mathrm{CO}_{2}$ signals, with no measureable change of the $\mathrm{CH}_{4}$ mole fraction and a deviation of $\pm 0.05 \mathrm{ppm}$ for $\mathrm{CO}_{2}$. A significant bias was observed for the VURF instrument, with an amplitude of approximately $5 \mathrm{ppb}$. This clearly indicates that this technique can only be implemented in environmentally controlled conditions. Very significant but low deviations in terms of absolute values were observed for the two QCL-based techniques. The range of the bias was within $(-0.4 /+1.1) \mathrm{ppb}$ for the ICOS-QCL instrument and within $(-1.1 /+1.8) \mathrm{ppb}$ for the Mini-QCL, which is below the WMO GAW DQOs. However, in order to reach the maximum achievable performance, these instruments need to be operated in well air-conditioned environments. Improvements of the internal temperature control of the analysers are still possible, and the ICOS-QCL instrument, for example, is now also available with an active temperature control that was not yet implemented in the instrument used for this study.

\subsubsection{Linearity}

The instruments were tested for linearity using either dilution of a high (ppm) CO standard with CO-free zero air (VURF instrument) or a manometric preparation of small $3 \mathrm{~L}$ flasks by adding a known amount of $\mathrm{CO}$ (using a standard with high $\mathrm{CO}$ mole fraction) to $\mathrm{CO}$-free air. For the flask preparation, the $\mathrm{CH}_{4}$ content of the high (ppm) standard was also known, and the dilution air was $\mathrm{CH}_{4}$-free (methane-free synthetic air for the flask preparation). The flasks were then analysed for methane using a Picarro $\mathrm{G} 1301 \mathrm{CH}_{4} / \mathrm{CO}_{2} / \mathrm{H}_{2} \mathrm{O}$ analyser, which allowed an independent check of the dilution ratios of the manometrically prepared flasks. Figure 6 shows the results of the linearity assessments for all instruments. It can be seen that all instruments except the ICOS-QCL analyser were linear within the uncertainties of the experimental setup 

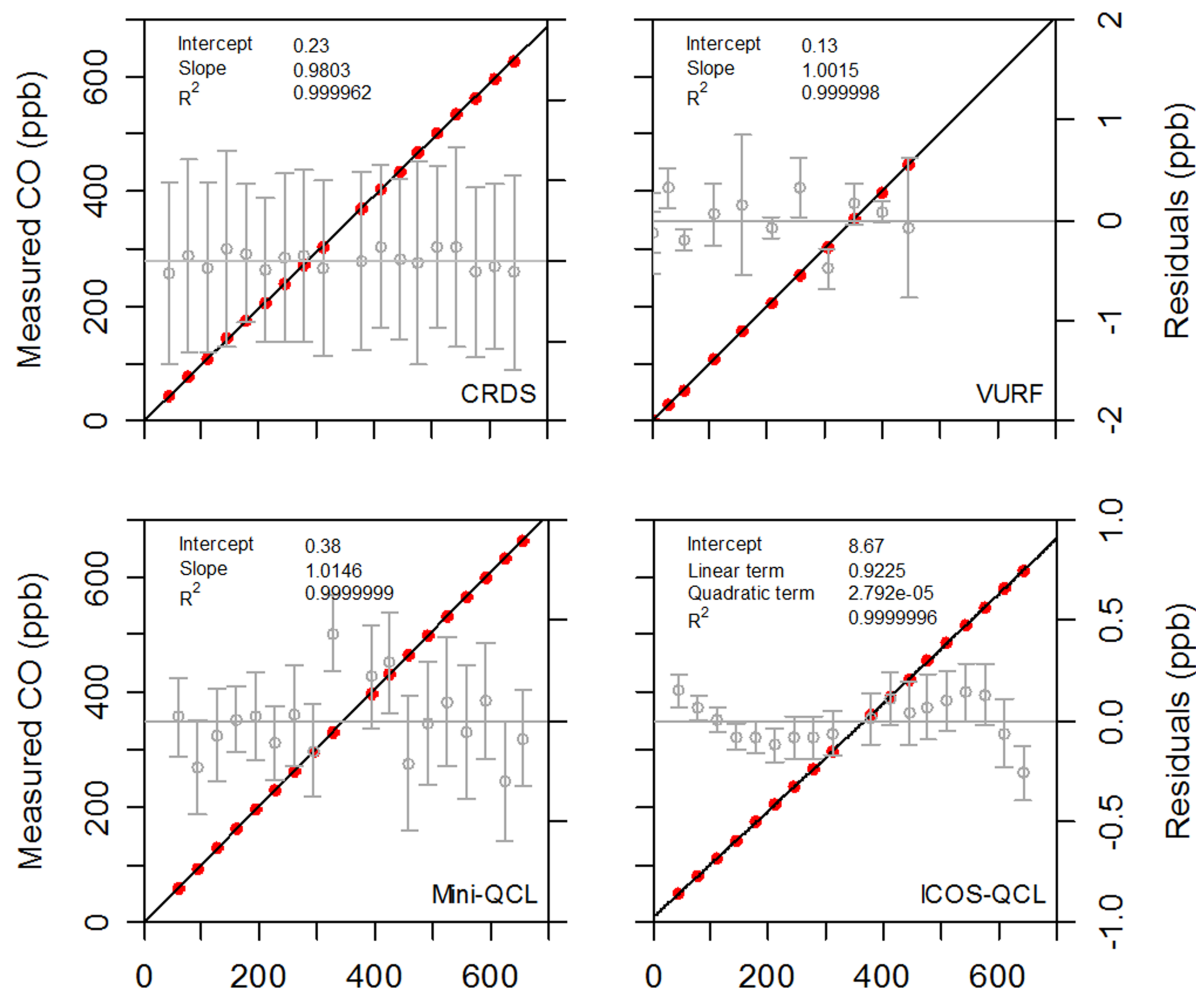

$\mathrm{CO}$ calculated from dilution $(\mathrm{ppb})$

CO calculated from dilution (ppb)

Fig. 6. Linearity plots for all instruments, including a fitted regression line and the regression residuals (open grey circles, right axis). Linear fits were applied for all techniques except ICOS-QCL (quadratic fit). Please take note of the different right-hand y-axis scales for the different panels.

in the range of 0 to $700 \mathrm{ppb} \mathrm{CO}$. For the ICOS-QCL analyser an appropriate quadratic calibration function was applied to characterise the instrument response function. The regression residuals were within $\pm 2 \mathrm{ppb}$ for all techniques and within $\pm 0.2 \mathrm{ppb}$ for the Mini-QCL instrument. The upper limit of the linear range was also tested and for the VURF and MiniQCL instruments was found to be approximately $1.5 \mathrm{ppm}$ $\mathrm{CO}$, and up to $20 \mathrm{ppm} \mathrm{CO}$ for the CRDS analyser.

\subsubsection{Water vapour correction}

Atmospheric water vapour mole fractions vary from a few ppm to several per cent in the troposphere. $\mathrm{CO}$ as well as other trace gas measurements are usually referred in dry air mole fractions, and calibration gases are also dry. Therefore, in most cases, appropriate drying of the sample is necessary to account for the dilution by water vapour. However, instruments based on spectroscopic techniques often allow simultaneously measuring the water vapour content in addition to the target gas, and, consequently, a water vapour correction is theoretically possible. Such corrections can also include spectroscopic effects, e.g. pressure broadening of the spectroscopic lines. They have been successfully implemented for the measurements of $\mathrm{CO}_{2}$ and $\mathrm{CH}_{4}$ with CRDS instruments (Chen et al., 2010).

All of the tested $\mathrm{CO}$ analysers were measuring water vapour in addition to $\mathrm{CO}$ except for the VURF instrument. The sample air of the VURF instrument is dried with a builtin Nafion ${ }^{\circledR}$ drier, and dry air mole fractions are reported. Consequently, no further corrections are required for the VURF instrument, which was confirmed by humidifying a $\mathrm{CO}$ working standard (not shown). A potential loss of $\mathrm{CO}$ over the dryer is also not expected to bias the measurements, since both sample air and calibration gases pass through the dryer. The CRDS analyser collects both humid and dry mole fractions for $\mathrm{CH}_{4}$ and $\mathrm{CO}_{2}$, but the software version of our instrument only reported a $\mathrm{CO}$ mole fraction, which includes a correction of water vapour dilution and spectroscopic influences (Rella, 2010). The ICOS-QCL analyser reports both corrected and uncorrected mole fractions, whereas only humid results are reported for the Mini-QCL. However, the ICOS-QCL corrections are only based on the dilution by water vapour and do not consider other effects such as line pressure broadening. The $\mathrm{H}_{2} \mathrm{O}$ signals of the analysers were not calibrated since the analysers' $\mathrm{H}_{2} \mathrm{O}$ readings were only used 


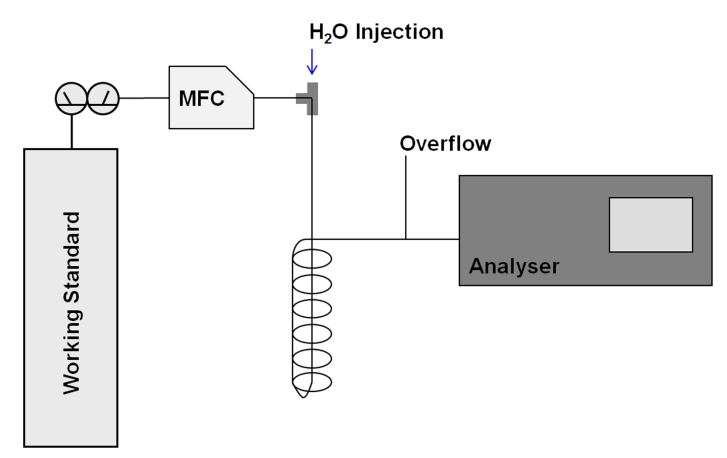

Fig. 7. Experimental setup for the determination of the water vapour interference.

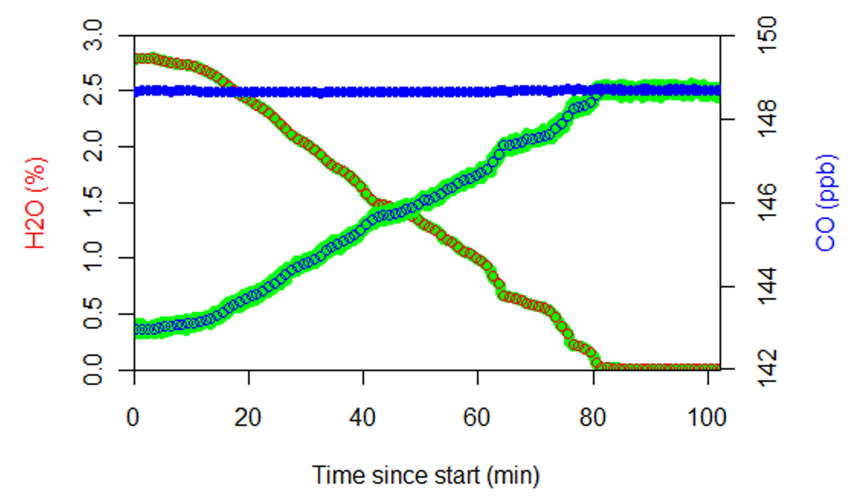

Fig. 8. Example of $\mathrm{CO}$ and $\mathrm{H}_{2} \mathrm{O}$ time series during the water vapour interference experiment with the ICOS-QCL analyser. Green circles are 1-s raw data, open circles are 1-min averages. The filled blue circles are water vapour-corrected 1-min CO data based on this experiment.

for correction and were not considered to be used for determination of absolute $\mathrm{H}_{2} \mathrm{O}$ mole fractions.

To determine the water vapour corrections or to assess the already implemented corrections of the analysers, the following experiments were carried out. A small amount of water (approximately $0.8 \mathrm{ml}$ ) was directly injected into a Synflex1300 coil, and a constant flow (approximately $500 \mathrm{ml} \mathrm{min}^{-1}$ ) of a working standard gas was delivered to the instrument. A schematic view of the measurement setup is shown in Fig. 7. With this setup, the working standard was humidified to up to $3 \%$ (corresponding to $30000 \mathrm{ppm}_{2} \mathrm{O}$ ) and then slowly dried to a few ppm within $1-2 \mathrm{~h}$. This gives a continuous coverage of the $0-3 \%$ humidity range whilst the dry $\mathrm{CO}$ mole fraction is kept constant. Compared to previous experimental setups (Chen et al., 2010; Winderlich et al., 2010), this setup has the advantage that a complete coverage of the relevant water vapour mixing ratios can be achieved. It further does not require a sophisticated setup and is consequently rather straightforward to be performed both in field and laboratory experiments. An example time series is plotted in Fig. 8 for the ICOS-QCL instrument. The water vapour influence can now be expressed with sufficient agreement by a quadratic fit,

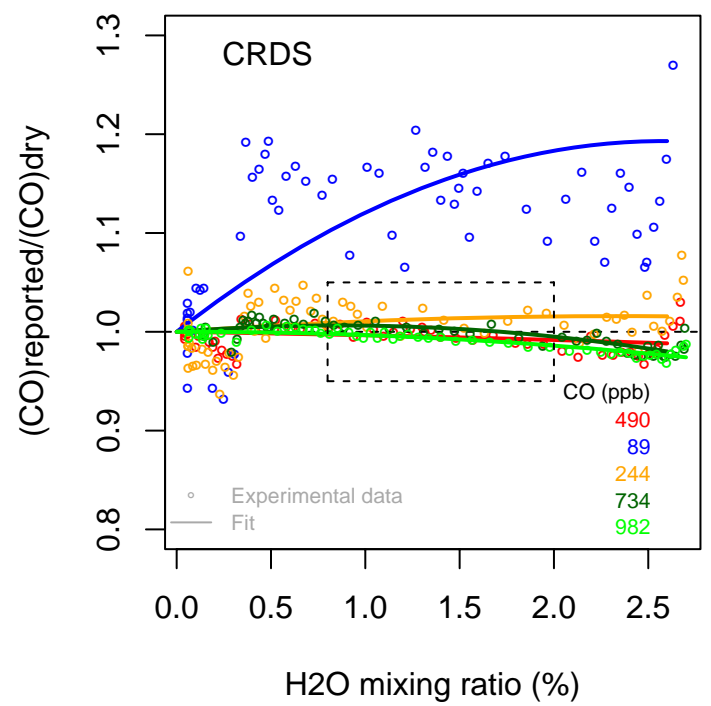

Fig. 9. Ratios of $\mathrm{CO}_{\text {reported }} / \mathrm{CO}_{\text {dry }}$ mole fractions vs. water vapour mixing ratios of the CRDS instrument for different $\mathrm{CO}$ levels. The black dotted line indicates a perfect correction of the reported $\mathrm{CO}$ mole fraction. The box denotes conditions encountered during the ambient air comparison (see Sect. 3.2).

$\mathrm{CO}_{\text {wet }} / \mathrm{CO}_{\text {dry }}=1+a \times \mathrm{H}_{2} \mathrm{O}+b \times\left(\mathrm{H}_{2} \mathrm{O}\right)^{2}$. Such experiments were performed with varying $\mathrm{CO}$ levels (all instruments) and at different operating pressures (Mini-QCL only). The operating pressure was varied for the Mini-QCL instrument in order to assess this effect for this instrument, since the pressure in the measurement cell was not actively controlled in our analyser. The results of the $\mathrm{CO}_{\text {wet }} / \mathrm{CO}_{\text {dry }}$ ratios vs. the $\mathrm{H}_{2} \mathrm{O}$ mixing ratio are presented in Figs. 9 to 11. The CRDS instrument reports a CO mole fraction that is corrected for cross sensitivities, and $\mathrm{CO}_{\text {reported }} / \mathrm{CO}_{\text {dry }}$ ratios were calculated for this instrument, which was done to verify if the implemented correction function correctly compensates for dilution and spectroscopic effects. In this case, the $\mathrm{CO}_{\text {reported }} / \mathrm{CO}_{\text {dry }}$ ratios should be 1 and should not depend on the $\mathrm{H}_{2} \mathrm{O}$ mixing ratio. However, the tested analyser showed a clear relationship between water vapour and $\mathrm{CO}$ mole fraction; low $\mathrm{CO}$ mole fractions tend to be overestimated in the presence of water. It can be seen from Figs. 10 and 11 that the $\mathrm{CO}$ mole fraction is underestimated due to pressure broadening effects for the instruments without implemented corrections (Mini-QCL and ICOS-QCL). However, correction functions can be applied for both analysers. These functions proved to be quite stable and independent of the $\mathrm{CO}$ mole fraction for the ICOS-QCL instrument and for the Mini-QCL instrument; however, for the latter, the differences between different mole fractions were slightly larger. No significant change of the Mini-QCL instrument behaviour could be observed due to variations of the cell pressure within a range of $53 \pm 10$ Torr (see Fig. 10). The picture looked significantly different for the CRDS instrument (Fig. 9). For this 


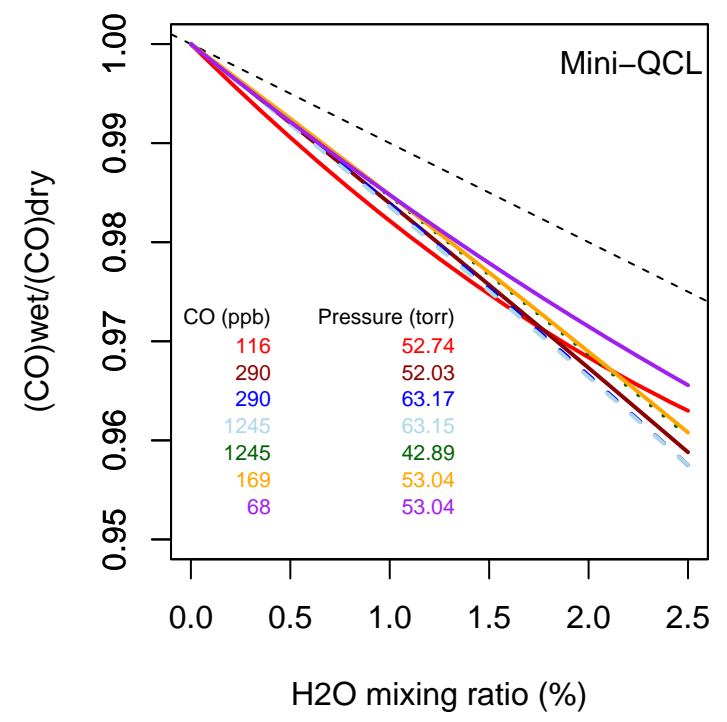

Fig. 10. Water vapour correction function for different $\mathrm{CO}$ mole fractions and operating pressures of the Mini-QCL instrument (coloured lines) and the effect of dilution (black dashed line).

instrument, the correction functions are more difficult to derive experimentally due to larger signal-to-noise ratios compared to the QCL instruments. Nevertheless, it can be seen that the $\mathrm{CO}$ mole fractions were overestimated in the order of roughly $10-20 \%$ for low mole fractions, whereas higher mole fractions tended to be slightly underestimated. Based on this experiment, it is clear that the implemented correction function of the tested CRDS analyser was not optimal for low $\mathrm{CO}$ mole fractions. The analysis also revealed that the difference of $\mathrm{CO}_{\text {reported }}-\mathrm{CO}_{\text {dry }}$ is not a suitable measure as it did not produce a consistent pattern when plotting vs. $\mathrm{H}_{2} \mathrm{O}$ (not shown here).

In order to estimate the contribution of the water vapour correction to the overall uncertainty of the $\mathrm{CO}$ measurements, the maximum difference between the different correction functions was calculated for a humidity of $2.5 \%$. For the Mini-QCL instrument, a maximum difference of $0.81 \%$ was observed within a mole fraction range of 68 to $1245 \mathrm{ppb}$ $\mathrm{CO}$ as well as with different operating pressures of the instrument. For the ICOS-QCL analyser, the maximum difference was $0.26 \%$; however, only a smaller mole fraction range of 57 to $262 \mathrm{ppb} \mathrm{CO}$ was covered. In both cases, the WMO GAW DQOs of \pm 2 ppb would be achieved for typical ambient CO mole fractions up to $250 \mathrm{ppb}$. In contrast, the maximum difference between the correction functions in the range of 89 to $982 \mathrm{ppb}$ CO was $21.5 \%$ for the CRDS instrument; especially low mole fractions were overestimated in the presence of water. The CRDS instrument tested during this study was the first instrument that was rolled out (serial number \#2001); in the meantime, further optimisations were implemented. Since the measurements of $\mathrm{CO}$ are performed in the near-infrared region, where also $\mathrm{H}_{2} \mathrm{O}$ and $\mathrm{CO}_{2}$ are

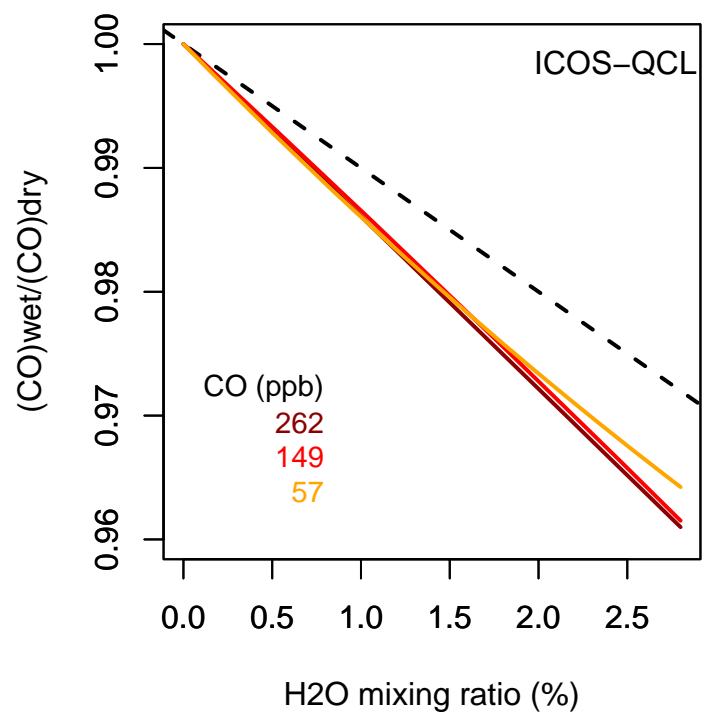

Fig. 11. Water vapour correction function for different $\mathrm{CO}$ mole fractions of the ICOS-QCL instrument (coloured lines) and the effect of dilution (black dashed line).

interfering, these effects have to be quantified and appropriate corrections are needed. Figure 12 shows the corrected CO mole fraction for a recently produced Picarro G2401 instrument (serial number \#2028) with optimised compensation of the $\mathrm{CO}_{2}$ and $\mathrm{H}_{2} \mathrm{O}$ interferences. The $\mathrm{CO}$ mole fraction was varied between 66 and $246 \mathrm{ppb}$, and the experiments were done for two different $\mathrm{CO}_{2}$ levels. It can be seen that the corrected $\mathrm{CO}$ mole fraction of the optimised instrument is not significantly influenced by the $\mathrm{CO}_{2}$ and $\mathrm{H}_{2} \mathrm{O}$ levels, which indicates that the corrections adequately account for the $\mathrm{CO}_{2}$ and $\mathrm{H}_{2} \mathrm{O}$ interferences.

\subsubsection{Summary of the analyser performance tests}

Our study complements a previously published CO comparison (Zellweger et al., 2009) and gives an update of current measurement techniques with the exception of the FTIR method (Griffith et al., 2012). This technique has recently become commercially available and has the potential for providing compatible $\mathrm{CO}$ data. First instrument performance tests of an FTIR analyser have recently been published (Hammer et al., 2012). The results of our instrument tests are summarised in Table 1. It can be seen that compatible data within the WMO GAW DQOs of \pm 2 ppb can be achieved with all techniques if the averaging time is sufficiently long. However, the Mini-QCL and ICOS-QCL instruments allow very fast and precise measurements even at $1-\mathrm{Hz}$ temporal resolution. Drift potentially compromises measurements taken with the VURF and also the Mini-QCL instruments. Thus, appropriate calibration schemes are required for these instruments. All CO data of the tested instruments with the exception of the CRDS technique were 
Table 1. Performance summary of the tested $\mathrm{CO}$ analysers.

\begin{tabular}{llllll}
\hline & VURF & CRDS & Mini-QCL & ICOS-QCL & FTIR \\
\hline Precision 1 s (ppb) & 1.1 & 11.2 & 0.06 & 0.11 & \\
Precision 1 min (ppb) & 0.7 & 2.5 & 0.04 & 0.07 & 0.20 \\
Precision 10 min (ppb) & 0.25 & 1.0 & 0.05 & 0.07 & 0.08 \\
Maximum drift $\left(\mathrm{ppb} \mathrm{h}^{-1}\right)$ & $<0.5$ & ND & 0.3 & 0.1 & \\
Linearity (Range in ppb) & $0-2500$ & $0-20000$ & $0-1500$ & 2 nd order & $90-620$ \\
Temperature changes & - & ++ & - & - & - \\
$\mathrm{H}_{2} \mathrm{O}$ correction & NA & $-{ }^{* *}$ & ++ & ++ & NA $^{* * *}$ \\
\hline
\end{tabular}

ND: Not detectable; NA: Not applicable; (-) to (++): weaker to stronger performance (qualitative).

${ }^{*}$ Results from Hammer et al. (2012) and Griffith et al. (2012). ${ }^{* *}$ The tested instrument showed weak performance for low mole fractions; in the meantime, correction algorithms have been improved. ${ }^{* * *} \mathrm{H}_{2} \mathrm{O}$ correction is not applicable because the sample air is dried.
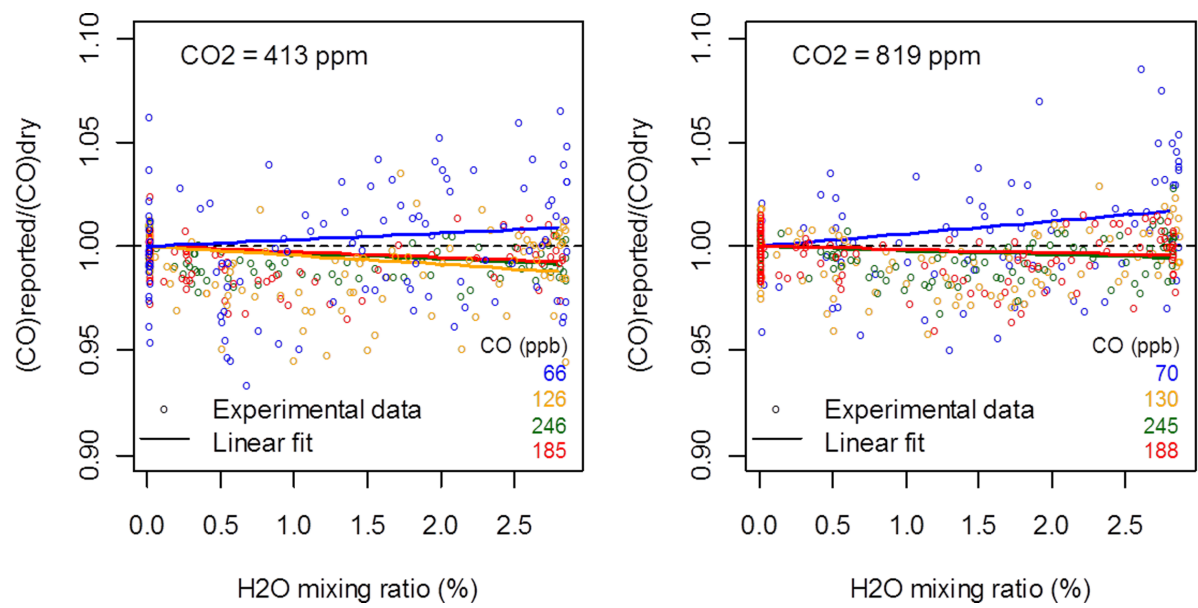

Fig. 12. Ratios of $\mathrm{CO}_{\text {reported }} / \mathrm{CO}_{\text {dry }}$ mole fractions vs. the water vapour mixing ratios of a Picarro G2401 CRDS instrument with optimised water vapour correction function for different $\mathrm{CO}$ levels. The experiment was done at two different $\mathrm{CO}_{2}$ mole fractions (left: 413 ppm $\mathrm{CO}_{2}$, right: 819 ppm $\mathrm{CO}_{2}$ ).

further influenced by temperature changes of the laboratory; this obviously needs to be improved for continuous operation of these instruments in the field, since many measurement stations are not sufficiently air-conditioned. Currently, improvements have been made on the latest ICOS-QCL instruments (enhanced performance package), but they have not yet been tested. It was shown that a water vapour correction is possible for all instruments; however, correction functions have to be determined for each individual instrument and need to be verified in regular time intervals as well.

\subsection{Ambient air comparison}

The instruments described above measured ambient air over a 4-day period using a common air inlet. The measurements were taken at Dübendorf, a suburban area of Zürich, Switzerland. This measurement site is representative of suburban background mixing ratios of $\mathrm{CO}$, but they can be influenced mainly by traffic emissions of nearby roads (Steinbacher et al., 2007). The residence time in the air inlet system was minimised to avoid a time lag between the measurements of the different instruments. A time series plot of 1-h values for all four instruments as well as the difference to the ICOS-QCL analyser are shown in Fig. 13. It can be seen that the $\mathrm{CO}$ mole fraction was highly variable and ranged from 100 to $500 \mathrm{ppb}$. This covers most of the $\mathrm{CO}$ mole fraction range which normally occurs in ambient air, although very low mole fractions are not covered by the current study. The CRDS instrument was initially calibrated using a suite of NOAA/ESRL standards, and the calibration was verified by additional measurements of working standards. The QCL and ICOS-QCL instruments were initially calibrated with a suite of six Empa working standards and four NOAA/ESRL standard gases covering the $\mathrm{CO}$ mole fraction range from 0 to $1170 \mathrm{ppb}$. During the ambient air comparison, two working standards were measured every $11.5 \mathrm{~h}$ on all instruments except the VURF analyser, which was automatically calibrated every $3 \mathrm{~h}$ using another working standard. The VURF working standard was traced back to the same NOAA/ESRL standards that were used for the initial calibration of the other analysers. With this calibration scheme, traceability of all 
Table 2. Results of the orthogonal regression analysis between the different measurement techniques. $X$ and $Y$ are the corresponding instruments, a is the intercept, and $\mathrm{b}$ is the slope of the regression with standard uncertainties $(k=1) . R^{2}$ is the coefficient of determination and $N$ is the number of data points (1-h values).

\begin{tabular}{llrccc}
\hline$Y$ & $X$ & $a[\mathrm{ppb}]$ & $b$ & $R^{2}$ & $N$ \\
\hline Mini-QCL & ICOS-QCL & $1.14 \pm 0.17$ & $0.9921 \pm 0.0001$ & 0.99996 & 97 \\
Mini-QCL & VURF & $2.66 \pm 0.29$ & $0.9919 \pm 0.0015$ & 0.99989 & 97 \\
Mini-QCL & CRDS & $2.21 \pm 0.45$ & $0.9851 \pm 0.0024$ & 0.99971 & 97 \\
ICOS-QCL & VURF & $2.54 \pm 0.25$ & $0.9927 \pm 0.0014$ & 0.99991 & 97 \\
ICOS-QCL & CRDS & $2.10 \pm 0.46$ & $0.9859 \pm 0.0025$ & 0.99970 & 97 \\
VURF & CRDS & $-0.42 \pm 0.53$ & $0.9931 \pm 0.0029$ & 0.99960 & 97 \\
\hline
\end{tabular}
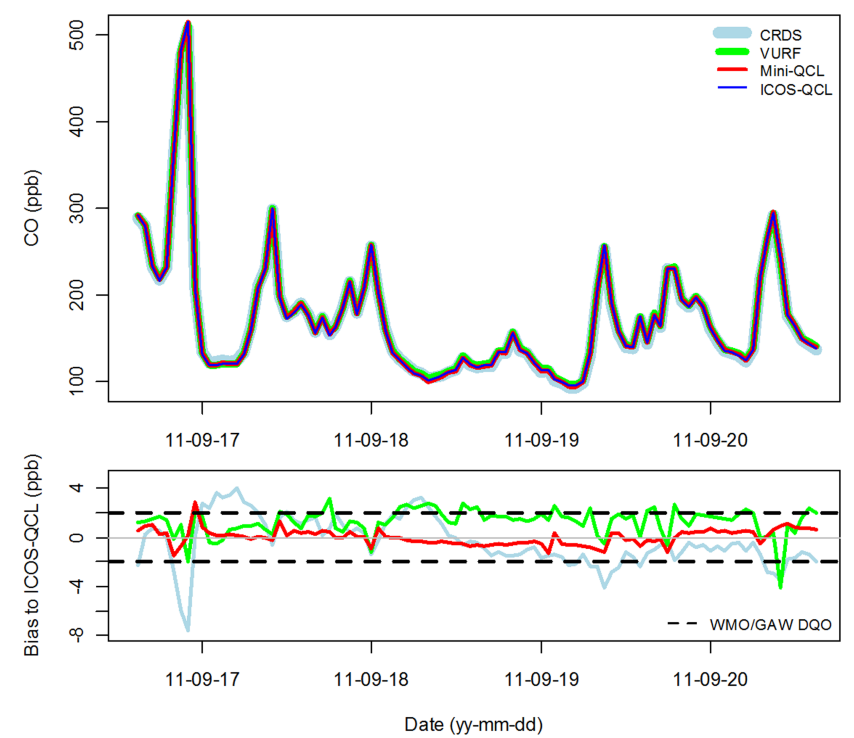

Fig. 13. Ambient air CO mole fractions measured with four different $\mathrm{CO}$ analysers from Friday, 16 September, to Tuesday, 20 September 2011 (upper panel), and difference to the ICOS-QCL analyser (lower panel). 1-h averages are shown.

measurements to the same set of NOAA/ESRL standards on the WMO-2004 carbon monoxide scale (Novelli et al., 2003 ) is ensured. The Mini-QCL and the ICOS-QCL were calibrated after the comparison based on the working standard measurements, and no further corrections were applied to the CRDS data due to the relatively high instrumental noise of individual working standard measurements with this instrument.

It can be seen from Fig. 13 that most of the 1-h data were within $\pm 2 \mathrm{ppb}$ (DQOs) for all instruments, although the VURF measurements were slightly higher compared to the other techniques. Relative difference histograms are shown in Fig. 14; no significant bias on the $95 \%$ confidence level $(k=2)$ compared to the ICOS-QCL was observed for any of the instruments based on 1-h values. However, a significant bias of $+0.94 \pm 0.16 \%(k=2)$ was observed for the VURF analyser over the entire period, whereas the biases of the CRDS $(-0.07 \pm 0.13 \%, k=2)$ and the Mini-QCL
$(-0.02 \pm 0.08 \%, k=2)$ instruments were not significant. Table 2 summarises the regression parameters of an orthogonal regression analysis (York, 1966) for all possible instrument combinations. All four measurement techniques were highly correlated $\left(R^{2}>0.999\right)$. Such high correlations are only possible if (a) the instruments are properly calibrated over the measured mole fraction range, (b) the repeatability and reproducibility is sufficiently good for the applied averaging time, (c) the instruments are reacting comparably fast to mole fraction changes in the measured air, (d) the temporal coverage of the measurement is able to capture short-term variation within the applied averaging time, and (e) no interference with other species occurs.

Based on the above discussed instrument performance tests, good results could have been expected for most of the above points (a-e), which are briefly discussed in the following:

a. Calibration: With the exception of the ICOS-QCL instrument, all analysers were entirely linear within the uncertainty of the measurements set up over the mole fraction range measured during the comparison. The ICOS-QCL raw data were first corrected for nonlinearity based on the calibration function determined during the linearity experiment (Fig. 6) and then calibrated based on the comparisons with the working standards. This procedure adequately determines the calibration function. During our study, all instruments were calibrated with working standards that were traceable to a common set of NOAA reference standards. Traceability to a common reference is important (Buchmann et al., 2009), since a lack of appropriate standards may result in a significant bias between different time series (Ou Yang et al., 2009).

b. Repeatability and reproducibility: The instrument precision (repeatability of raw data over a time period that is short enough to be unaffected by drift) is sufficiently good for all instruments, but large differences exist between different techniques (Fig. 1). However, the averaging time of one hour results in compatible data for all techniques. Instrument drift, which potentially influences the reproducibility of measurements, was 


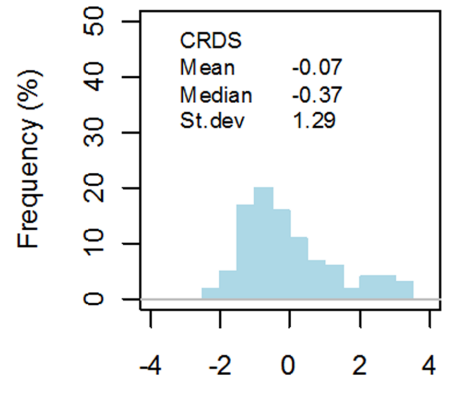

Deviation to ICOS-QCL (\%)

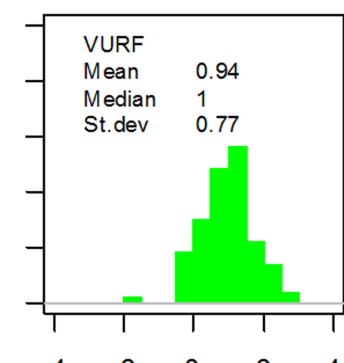

Deviation to ICOS-QCL (\%)

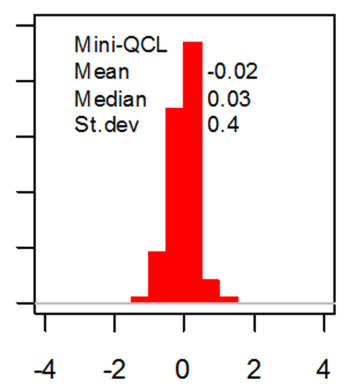

Deviation to ICOS-QCL (\%)

Fig. 14. Histogram of the deviations of the different instruments relative to the ICOS-QCL in per cent during the ambient air measurements.

an issue mainly for the VURF and the Mini-QCL instruments. Frequent automatic calibrations sufficiently compensated these effects for the VURF instrument; the drift of the Mini-QCL instrument potentially explains part of the observed deviations compared to the ICOSQCL instrument, since a bias of up to $1 \mathrm{ppb}$ can be expected based on results of the drift experiment (Fig. 2). It should be noted that such stable results can only be achieved in well air-conditioned environments; drift would become a much more serious issue if the laboratory temperature varied, and more frequent calibration intervals would be required to account for this.

c. Reaction time: The instruments were able to capture changes in mole fractions sufficiently fast to avoid a significant bias due to different reaction times. The sample's residence time in the inlet to the various instruments was made as short as possible by using bypass pumps to flush the inlet lines. The reaction times of the analysers themselves depend mainly on the flow rate and the volume of the measurement cells. The flushing time is variable for the Mini-QCL and the ICOS-QCL instruments, but these instruments were also operated with relatively low flow rates of about $200 \mathrm{ml} \mathrm{min}^{-1}$, which is sufficient for capturing changes in mole fractions as they occurred during the comparison.

d. Temporal coverage: All instruments used in this work are continuous techniques, and data loss occurs only during calibrations including some time with transient data between changes from ambient air to calibration gas. Since ambient CO data can be highly variable on short terms even during periods with relatively stable hourly values, a complete temporal coverage is important for accurate measurements of hourly data. For example, Zellweger et al. (2009) found the highest correlations between continuous techniques for $\mathrm{CO}$ measurements taken at Jungfraujoch $\left(R^{2}=0.992\right)$, despite the fact that a non-dispersive infrared (NDIR) instrument, which shows significant short-term noise, was compared against a VURF instrument. Significantly lower but still very significant correlations $\left(R^{2}\right.$ between 0.935 and 0.981 ) were observed at Jungfraujoch when quasicontinuous gas chromatographic techniques were compared. In the current study, $R^{2}$ was higher than 0.999 for all possible instrument combinations. This clearly indicates that the frequency and temporal averaging of the instrument signal cannot be neglected in locations of high short-term CO change.

e. Interferences: The main potentially interfering molecule is water. The air was dried in the VURF analyser with a Nafion dryer, and corrections were applied to the QCL instruments. The CRDS instrument was only reporting $\mathrm{H}_{2} \mathrm{O}$-corrected $\mathrm{CO}$ mole fractions; however, the correction algorithm of this instrument was shown to be insufficient for mole fractions below $100 \mathrm{ppb}$ CO. During the comparison, the water vapour mixing ratio approximately ranged from 0.8 to $2.0 \%$ (CRDS raw data), whereas all $\mathrm{CO}$ mole fractions were above $100 \mathrm{ppb}$. Within this $\mathrm{CO}$ and $\mathrm{H}_{2} \mathrm{O}$ range (indicated by the box in Fig. 9), the correction used by the CRDS instrument was sufficiently good to account for interferences and dilution effects. However, a significant bias in the order of 10-20\% would be expected for CO mole fractions below $100 \mathrm{ppb}$. The correction implemented in the CRDS instrument also accounts for cross-talk between $\mathrm{CO}$ and $\mathrm{CO}_{2}$; a test with constant $\mathrm{CO}$ of approximately $260 \mathrm{ppb}$ and varying $\mathrm{H}_{2} \mathrm{O}(0-3 \%)$ and $\mathrm{CO}_{2}(178-1321 \mathrm{ppm})$ did not show any dependency in the corrected data (not shown). The good agreement between the other techniques indicates that the correction functions applied to the QCL instruments were appropriate and constant over time.

\section{Conclusions}

The current study complements a previously published CO instrument comparison (Zellweger et al., 2009) and gives an update of current measurement techniques with the exception of the FTIR method, which has been recently assessed 
by Hammer et al. (2012). It could be demonstrated that new spectroscopic measurement techniques (QCL, CRDS) are suitable for high precision carbon monoxide measurements in ambient air as well as for the calibration of standards. In addition, they require less maintenance and manpower compared to other techniques. Operational costs are also relatively low since these techniques do not use expensive consumables and have a low consumption of calibration gases due to their stability (low drift and linearity). A further advantage is the simultaneous detection of several species (e.g. QCL: $\mathrm{CO}, \mathrm{N}_{2} \mathrm{O}, \mathrm{H}_{2} \mathrm{O}$; CRDS: $\mathrm{CO}, \mathrm{CH}_{4}, \mathrm{CO}_{2}$, and $\mathrm{H}_{2} \mathrm{O}$ ). However, the initial capital investment is higher compared to NDIR or GC techniques. Compared to the VURF technique, a better performance in the range of one order of magnitude is achieved with QCL instruments and even up to two or more magnitudes compared to the CRDS and NDIR techniques. However, $\mathrm{CO}$ measurements fulfilling the current WMO data quality objectives of \pm 2 ppb are possible with these techniques if appropriate averaging intervals (in the order of one hour) are applied. All investigated methods of the current study have the advantage that they have a continuous temporal coverage of the analysed air, which results in significantly higher compatibility of these methods compared to techniques with a quasi-continuous temporal coverage (e.g. GC methods).

It could further be shown that the QCL and CRDS measurements can be taken without sample air drying, and a correction of the dilution and spectroscopic effects of water vapour can be applied to the measured values. Tests with most recent versions of CRDS analysers also revealed that effects of the $\mathrm{CO}_{2}-\mathrm{CO}$ cross-talk can be properly accounted for in the software. However, a few issues such as temperature dependence and imperfect compensation of spectroscopic interferences were identified and need further investigation, and technical improvements of the analysers are still possible.

The instruments were successfully deployed during a field measurement campaign; it could be demonstrated that measurements within the current WMO GAW DQOs of $\pm 2 \mathrm{ppb}$ for $\mathrm{CO}$ are possible with all investigated techniques if they are appropriately operated and calibrated.

Acknowledgements. The work was supported by MeteoSwiss through engagement in the Global Atmosphere Watch Programme. The Mini-QCL instrument was funded by the Swiss National Air Pollution Monitoring Network (NABEL) in collaboration with the Swiss Federal Office for the Environment (FOEN). The authors would like to thank Picarro Inc. and Los Gatos Research for providing instruments for testing.

Edited by: O. Tarasova

\section{References}

Baer, D. S., Paul, J. B., Gupta, M., and O'Keefe, A.: Sensitive absorption measurements in the near-infrared region using off-axis integrated-cavity-output spectroscopy, Appl. Phys. B, 75, 261265, doi:10.1007/s00340-002-0971-z, 2002.

Buchmann, B., Klausen, J., and Zellweger, C.: Traceability of Long-Term Atmospheric Composition Observations across Global Monitoring Networks, Chimia, 63, 657-660, doi:10.2533/chimia.2009.657, 2009.

Chen, H., Winderlich, J., Gerbig, C., Hoefer, A., Rella, C. W., Crosson, E. R., Van Pelt, A. D., Steinbach, J., Kolle, O., Beck, V., Daube, B. C., Gottlieb, E. W., Chow, V. Y., Santoni, G. W., and Wofsy, S. C.: High-accuracy continuous airborne measurements of greenhouse gases $\left(\mathrm{CO}_{2}\right.$ and $\left.\mathrm{CH}_{4}\right)$ using the cavity ringdown spectroscopy (CRDS) technique, Atmos. Meas. Tech., 3, 375-386, doi:10.5194/amt-3-375-2010, 2010.

Crosson, E. R.: A cavity ring-down analyzer for measuring atmospheric levels of methane, carbon dioxide, and water vapor, Appl. Phys. B, 92, 403-408, doi:10.1007/s00340-008-3135-y, 2008.

Fried, A., Henry, B., Parrish, D. D., Carpenter, J. R., and Buhr, M. P.: Intercomparison of Tunable Diode-Laser and Gas Filter Correlation-Measurements of Ambient Carbon-Monoxide, Atmos. Environ. A, 25, 2277-2284, 1991.

Gerbig, C., Schmitgen, S., Kley, D., Volz-Thomas, A., Dewey, K., and Haaks, D.: An improved fast-response vacuum-UV resonance fluorescence CO instrument, J. Geophys. Res.-Atmos., 104, 1699-1704, 1999.

Griffith, D. W. T., Deutscher, N. M., Caldow, C., Kettlewell, G., Riggenbach, M., and Hammer, S.: A Fourier transform infrared trace gas and isotope analyser for atmospheric applications, Atmos. Meas. Tech., 5, 2481-2498, doi:10.5194/amt-5-2481-2012, 2012.

Gros, V., Bonsang, B., and Sarda Esteve, R.: Atmospheric carbon monoxide "in situ" monitoring by automatic gas chromatography, Chemosphere, 1, 153-161, doi:10.1016/s14659972(99)00010-0, 1999.

Hammer, S., Griffith, D. W. T., Konrad, G., Vardag, S., Caldow, C., and Levin, I.: Assessment of a multi-species in-situ FTIR for precise atmospheric greenhouse gas observations, Atmos. Meas. Tech. Discuss., 5, 3645-3692, doi:10.5194/amtd-5-3645-2012, 2012.

Logan, J. A., Prather, M. J., Wofsy, S. C., and McElroy, M. B.: Tropospheric Chemistry - a Global Perspective, J. Geophys. Res.Oceans, 86, 7210-7254, 1981.

McManus, J. B., Zahniser, M. S., Nelson, J. D. D., Shorter, J. H., Herndon, S., Wood, E., and Wehr, R.: Application of quantum cascade lasers to high-precision atmospheric trace gas measurements, Opt. Eng., 49, 111124-1-111124-11, 2010.

McManus, J. B., Zahniser, M. S., and Nelson, D. D.: Dual quantum cascade laser trace gas instrument with astigmatic Herriott cell at high pass number, Appl. Opt., 50, A74-A85, 2011.

Nedelec, P., Cammas, J.-P., Thouret, V., Athier, G., Cousin, J.-M., Legrand, C., Abonnel, C., Lecoeur, F., Cayez, G., and Marizy, C.: An improved infrared carbon monoxide analyser for routine measurements aboard commercial Airbus aircraft: technical validation and first scientific results of the MOZAIC III programme, Atmos. Chem. Phys., 3, 1551-1564, doi:10.5194/acp-3-15512003, 2003. 
Nelson, D. D., McManus, J. B., Herndon, S. C., Shorter, J. H., Zahniser, M. S., Blaser, S., Hvozdara, L., Muller, A., Giovannini, M., and Faist, J.: Characterization of a near-room-temperature, continuous-wave quantum cascade laser for long-term, unattended monitoring of nitric oxide in the atmosphere, Opt. Lett., 31, 2012-2014, doi:10.1364/ol.31.002012, 2006.

Novelli, P. C.: CO in the atmosphere: measurement techniques and related issues, Chemosphere, 1, 115-126, 1999.

Novelli, P. C., Masarie, K. A., Lang, P. M., Hall, B. D., Myers, R. C., and Elkins, J. W.: Re-analysis of tropospheric CO trends: Effects of the 1997-1998 wild fires, J. Geophys. Res.-Atmos., 108, 4464, doi:4410.1029/2002JD003031, 2003.

Ou Yang, C.-F., Lin, Y.-C., Lin, N.-H., Lee, C.-T., Sheu, G.-R., Kam, S.-H., and Wang, J.-L.: Inter-comparison of three instruments for measuring regional background carbon monoxide, Atmos. Environ., 43, 6449-6453, 2009.

Parrish, D. D., Holloway, J. S., and Fehsenfeld, F. C.: Routine, Continuous Measurement of Carbon-Monoxide with Parts-PerBillion Precision, Environ. Sci. Technol., 28, 1615-1618, 1994.

Provencal, R., Gupta, M., Owano, T. G., Baer, D. S., Ricci, K. N., O'Keefe, A., and Podolske, J. R.: Cavity-enhanced quantumcascade laser-based instrument for carbon monoxide measurements, Appl. Optics, 44, 6712-6717, 2005.

Rella, C.: Stable and Precise carbon monoxide measurements with the Picarro G2302, Picarro, Inc., Sunnyvale, California, 2010.

Steinbacher, M., Fischer, A., Vollmer, M. K., Buchmann, B., Reimann, S., and Hueglin, C.: Perennial observations of molecular hydrogen at a suburban site in Switzerland, Atmos. Environ., 41, 2111-2124, doi:10.1016/j.atmosenv.2006.10.075, 2007. van der Laan, S., Neubert, R. E. M., and Meijer, H. A. J.: A single gas chromatograph for accurate atmospheric mixing ratio measurements of $\mathrm{CO}_{2}, \mathrm{CH}_{4}, \mathrm{~N}_{2} \mathrm{O}, \mathrm{SF}_{6}$ and $\mathrm{CO}$, Atmos. Meas. Tech., 2, 549-559, doi:10.5194/amt-2-549-2009, 2009.

Werle, P., Mücke, R., and Slemr, F.: The Limits of Signal Averaging in Atmospheric Trace-Gas Monitoring by Tunable Diode-Laser Absorption Spectroscopy (TDLAS), Appl. Phys. B, 57, 131-139, 1993.

Winderlich, J., Chen, H., Gerbig, C., Seifert, T., Kolle, O., Lavric, J. V., Kaiser, C., Höfer, A., and Heimann, M.: Continuous lowmaintenance $\mathrm{CO}_{2} / \mathrm{CH}_{4} / \mathrm{H}_{2} \mathrm{O}$ measurements at the Zotino Tall Tower Observatory (ZOTTO) in Central Siberia, Atmos. Meas. Tech., 3, 1113-1128, doi:10.5194/amt-3-1113-2010, 2010.

WMO: Guidelines for the Measurement of Atmospheric Carbon Monoxide, GAW Report No. 192, World Meteorological Organization, Geneva, Switzerland, 2010.

WMO/GAW Glossary of QA/QC-Related Terminology: http:// gaw.empa.ch/glossary/glossary.html (last access: 12 September 2012), 2010.

York, D.: Least-Squares Fitting of a Straight Line, Can. J. Phys., 44, 1079-1086, 1966.

Zellweger, C., Hüglin, C., Klausen, J., Steinbacher, M., Vollmer, M., and Buchmann, B.: Inter-comparison of four different carbon monoxide measurement techniques and evaluation of the long-term carbon monoxide time series of Jungfraujoch, Atmos. Chem. Phys., 9, 3491-3503, doi:10.5194/acp-9-3491-2009, 2009. 